\title{
Derivation of Snow Water Equivalent in Boreal Forests Using Microwave Radiometry
}

\author{
J.L. FOSTER, ${ }^{1}$ A.T.C. CHANG, ${ }^{1}$ D.K. HALL, ${ }^{1}$ and A. RANGO ${ }^{2}$
}

(Received 6 June 1990; accepted in revised form 8 January 1991)

\begin{abstract}
Efforts have been made by several investigators to produce a reliable global microwave snow algorithm to estimate snow depth or snow water equivalent (snow volume) and snow extent. Complications arise when trying to apply a global algorithm to specific regions where the climate, snowpack structure and vegetation vary. In forest regions, the microwave emission from dense coniferous forests may overwhelm the emission from the underlying snow-covered ground. As a result, algorithms employing microwave data tend to underestimate snow depths. Preliminary results indicate that the amount of underestimation can be minimized when the fraction of forest cover can be accounted for and used as an additional input in microwave algorithms. In the boreal forest of Saskatchewan, the standard error between the measured and the estimated snow water equivalent was reduced from 2.7 to $2.1 \mathrm{~cm}$ by using a generalized snow retrieval algorithm that includes the percentage of forest cover. However, perhaps as much as $25 \%$ of the boreal forest of North America and Eurasia is too dense to enable satisfactory snow water equivalent determinations to be made using passive microwave techniques alone.
\end{abstract}

Key words: brightness temperature, boreal forest, microwaves, radiometer, snowpack

RÉSUMÉ. Plusieurs chercheurs ont tenté de créer un algorithme global fiable en vue d'estimer la profondeur de la neige ou l'équivalent d'eau de neige (volume nival) et l'étendue de neige à l'aide des micro-ondes. Les complications surgissent lorsqu'on essaye d'appliquer un algorithme global à des régions spécifiques où le climat, la structure de la neige accumulée et la végétation varient. Dans les régions forestières, l'émission de micro-ondes provenant des forêts denses de conifères peut prévaloir sur celle provenant du sol enfoui sous le couvert de neige. Il en résulte que les algorithmes qui utilisent les données des micro-ondes tendent à sous-estimer la profondeur de la neige au sol. Des résultats préliminaires indiquent que l'importance de la sous-estimation peut être réduite lorsqu'on fait entrer en ligne de compte la portion de couvert forestier et qu'on l'utilise comme une entrée supplémentaire dans les algorithmes de micro-ondes. Dans la forêt boréale de Saskatchewan, l'erreur normale entre l'équivalent d'eau de neige mesuré et celui estimé a été réduite de 2,7 à $2,1 \mathrm{~cm}$ lorsqu'on a utilisé un algorithme général pour retrouver la quantité de neige, algorithme qui tenait compte du pourcentage de couvert forestier. Il est cependant probable que jusqu'à 25 p. cent de la forêt boréale nord-américaine et eurasienne est trop dense pour permettre de déterminer de façon satisfaisante la quantité équivalente d'eau de neige en se servant uniquement de techniques passives de micro-ondes.

Mots clés: température de luminance, forêt boréale, micro-ondes, radiomètre, neige accumulée

Traduit pour le journal par Nésida Loyer.

\section{INTRODUCTION}

The boreal forests that stretch across the northern tier of North America and Eurasia provide a treasure trove of natural resources (Fig. 1). Probably the most ephemeral of these resources is the seasonal snowpack, which covers the ground for at least half of the year. With the advent of satellite technology the boreal forests are now easier to monitor, but in many areas information about the underlying surface is still difficult to extract.

Snow accumulates to deeper depths and melts later in the spring in the boreal forests than in adjacent tundra or prairie areas. The boreal areas are always snow covered during the winter months, but because the canopy can obscure much of the snowpack from the view of satellite sensors, making accurate estimates of snow depth or snow water equivalent (SWE) is a challenge. Since the boreal forest of the Northern Hemisphere constitutes approximately $15 \%$ of the lands normally covered by snow during the winter and upwards of $40 \%$ of the land surface normally snow covered during the autumn and spring, more reliable measures of the snow depth and snow-cover extent in boreal areas are needed for improved energy balance and water balance estimates.

In the Northern Hemisphere, the mean monthly snow cover ranges from about 7 to over $40 \%$ of the land area, thus making snow the most rapidly varying natural surface feature. The mean monthly snow storage (excluding Greenland) ranges from about $1.5 \times 10^{16} \mathrm{~g}$ in summer to about $300 \times$ $10^{16} \mathrm{~g}$ in winter (Chang et al., 1990a). Snow cover is a sensitive indicator of climate change, with the position of the southern boundary of snow cover in the Northern Hemisphere of particular significance, as it is likely to retreat northward if there is sustained climate warming (Barry, 1984). Snow depth is highly variable in forests, particularly when a mixture of small openings and stands of different species and sizes is present and when melting produces depth variations around individual trees. It is well known that to obtain a mean value that lies within the required confidence limits, the number of samples needed increases directly with the variance (Freese, 1962). In terms of a forest snow cover, many samples are required to provide a reliable mean snow depth because of the large variance involved. This can be expensive and time consuming and may not be practical in spring, when differential melt changes the snow distribution pattern rapidly from day to day (Woo and Steer, 1985).

The use of remote sensing techniques offers a way to complement and extend conventional ground-based measurements of snow to the regional and global scales. Passive microwave remote sensing is particularly suited to subpolar and polar latitudes, since these wavelengths are able to penetrate most clouds and are indifferent to varying degrees of daylight or darkness.

The objective of our study is to develop an improved algorithm for the retrieval of snow depth and snow water equivalent information in boreal forest areas using passive microwave satellite data. The methodology involved in microwave radiometric techniques and the problems encountered in determining the effects of vegetation on the microwave response in snow-covered areas are presented in the next two sections.

\footnotetext{
${ }^{1}$ Hydrological Sciences Branch (Code 974), NASA/Goddard Space Flight Center, Greenbelt, Maryland 20771, U.S.A.

${ }^{2}$ Agricultural Research Center Hydrology Laboratory, USDA/BARC-East, Beltsville, Maryland 20705, U.S.A.
} 


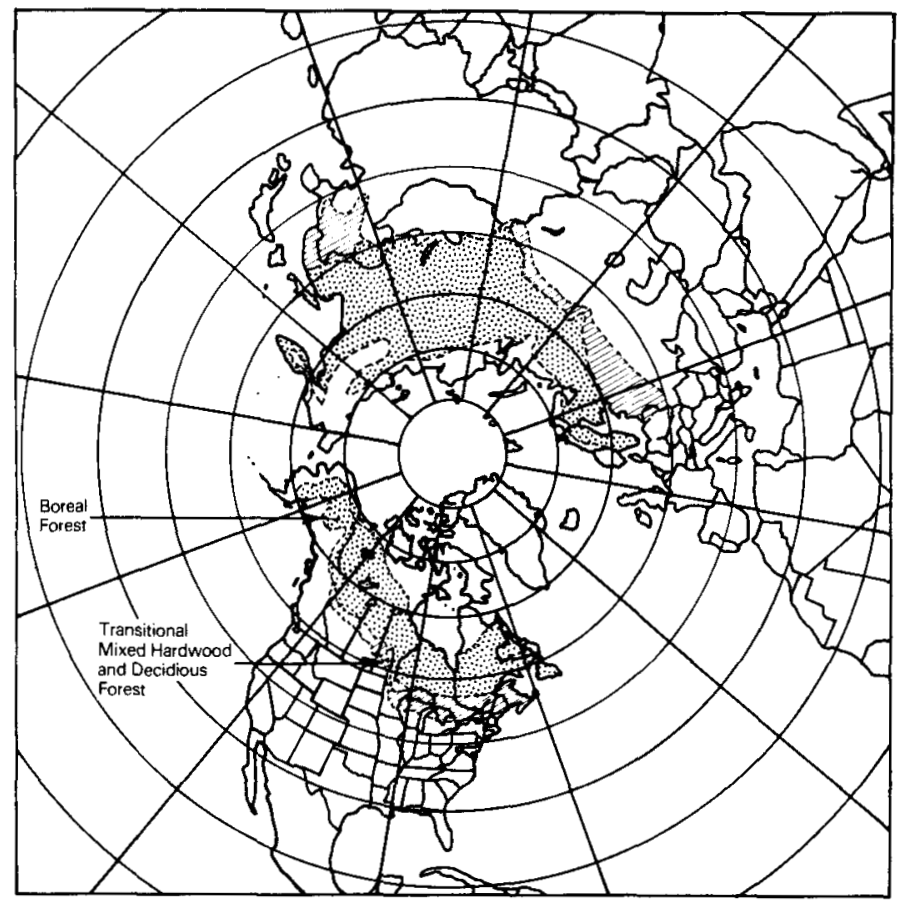

FIG. 1. Map showing the extent of the boreal forest in North America and Eurasia.

The study area is in the province of Saskatchewan, Canada (latitude $49^{\circ}-60^{\circ} \mathrm{N}$, longitude $101^{\circ}-110^{\circ} \mathrm{W}$ ). The northern part of the province (north of about $53^{\circ} \mathrm{N}$ ) is in the boreal forest, while the southern part is primarily prairie (Figs. 1 and 4). Lakes cover about $13 \%$ of the entire province but account for upwards of $25 \%$ of the surface area of the boreal forest. In the northern portion of the boreal forest, the Canadian Shield rock is expressed at the surface, resulting in a rock-strewn landscape with scrawny conifers (National Geographic Society, 1985).

\section{MICROWAVE RADIOMETRY}

Microwave emission from a layer of snow over a ground medium consists of two contributions: emission by the snow volume and emission by the underlying ground. Both contributions are governed by the transmission and reflection properties of the air-snow and snow-ground interfaces and by the absorption or emission and scattering properties of the snow layer (Stiles and Ulaby, 1980).

As an electromagnetic wave emitted from the underlying earth surface propagates through the snowpack, it is scattered by the randomly spaced snow particles in all directions. Consequently, when the wave emerges at the snow-air interface, its amplitude has been attenuated. Dry snow absorbs very little microwave energy from the wave; therefore, it also contributes very little in the form of self-emission. When the snowpack grows deeper, the wave encounters more scattering, and so less radiation is received by the sensor (Foster et al., 1987).

The effects of scattering microwave radiation by snow crystals have been reported by, among others, Chang et al. (1976), Kong et al. (1979), Rango et al. (1979), Tiuri and Hallikainen (1981), Kunzi et al. (1982), and Rott and Aschbacher (1989). Since November 1978, the Scanning Multichannel
Microwave Radiometer (SMMR) on the Nimbus-7 satellite has been acquiring passive microwave data that can be used to measure snow extent and calculate snow depth on an areal basis (Chang et al., 1987). The capability to compute estimates of global snow storage, hence the depth of snow, has been developed using algorithms derived from microwave radiometric measurements of snow using ground-based, airborne, and spaceborne observations.

In the algorithm developed by Chang et al. (1987) the snow water equivalent/brightness temperature relationship for a uniform snow field can be expressed as follows:

$$
\mathrm{SWE}=4.8 *\left(\mathrm{~T}_{18 \mathrm{H}}-\mathrm{T}_{37 \mathrm{H}}\right) \mathrm{mm}
$$$$
4.8 * \Delta \mathrm{T}_{\mathrm{B}}
$$

where SWE is the snow water equivalent and $T_{18 \mathrm{H}}$ and $T_{37 \mathrm{H}}$ are the brightness temperatures $\left(T_{B}\right)$ at 18 and $37 \mathrm{GHz}$ horizontal polarization. The constant 4.8 was derived by linearly fitting the theoretically calculated brightness temperatures assuming a mean snow crystal size of $0.3 \mathrm{~mm}$ and a snow density of $0.3 \mathrm{~g} / \mathrm{cm}^{3}$ (Chang et al., 1990c).

This algorithm has been used to generate global maps of snow volume and snow cover area. The SMMR data are interpolated for spatial and temporal gaps and averaged on a monthly basis into microwave brightness temperatures and displayed on color-coded maps using a polar stereographic projection. The maps are based on the average of six days of brightness temperature data taken during the middle of each month. The data are placed into $12^{\circ}$ latitude by $12^{\circ}$ longitude grid cells uniformly subdividing a polar stereographic map according to the geographic coordinates of the center of the field of view of the SMMR radiometers. Maps using a polar stereographic projection provide a synoptic representation of the brightness temperature data. A mask was constructed to remove brightness temperature data over oceans and bays so that only microwave data for land areas are displayed (Chang et al., 1990b).

There are, of course, complications that arise when one tries to apply an algorithm based on average snow conditions to specific regions where the climate, snowpack structure, and vegetation cover vary. The sensitivity of the SWE/brightness temperature relationship will be modified by differences in terrain and vegetation cover (Fig. 2). A method to correct for the absorption of the snow signal by the forest cover will be described in the next section.

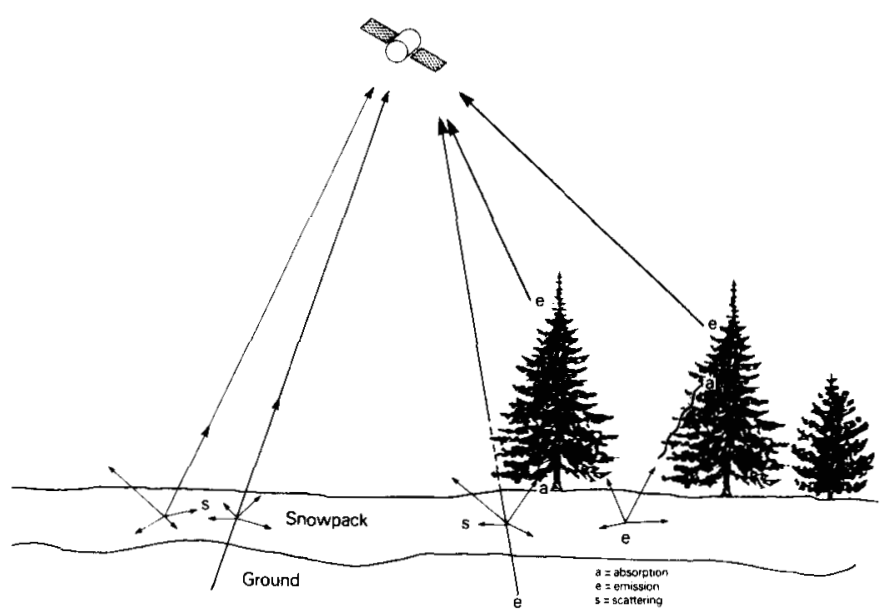

FIG. 2. Schematic showing scattering, emission, and absorption properties of snow and vegetation at $37 \mathrm{GHz}$. 


\section{VEGETATION EFFECTS ON PASSIVE MICROWAVES}

The vegetation canopy can be represented as a dielectric mixture consisting of discrete dielectric elements (leaves, stalks, branches, etc.) embedded in a matrix of air (Ulaby and Jedlicka, 1984). In the $37 \mathrm{GHz}$ region, vegetation is a strong absorber of microwave radiation and dominates the upwelling microwave radiation (Wang, 1985). Based on a radiative transfer model, Choudhury et al. (1987) found that the vertical and horizontal ( $\mathrm{V}$ and $\mathrm{H}$ ) polarization difference at $37 \mathrm{GHz}$ decreased rapidly with increasing vegetation and approached zero for vegetation with water content greater than $1 \mathrm{~kg} / \mathrm{m}^{2}$. For a pine-dominated forest the normalized surface emissivity derived from SMMR data is about $\mathbf{0 . 9 2}$ for both the 18 and $37 \mathrm{GHz}$ horizontal polarizations (Hallikainen et al., 1988).

The amount of thermal microwave radiation emerging from the earth's surface depends on the dielectric properties of the surface composition within each footprint or pixel. Since the passive microwave footprint is on the order of $20 \mathrm{~km}$ or larger, a mixture of features and surfaces within the footprints can be expected (Chang et al., in press).

A simple model to separate the effect of the forest cover from the effect of the snow depth was developed for the SMMR $37 \mathrm{GHz}$ channel (Hall et al., 1982). By assuming that trees are the primary influencing factor affecting the $T_{B} /$ snow depth relationship, the effective brightness temperature can be expressed as:

$T_{B R}=T_{B}-f T_{B T}$

where $T_{B R}$ represents the residual brightness temperature from which the effects of forest cover have been removed, $f$ is the percentage of forest cover of the SMMR footprint, and $T_{B T}$ is the assumed brightness temperature of the trees, which is calculated by multiplying the emissivity of the trees (0.9) by the average weekly maximum air temperature. A correlation coefficient of 0.8 between $T_{B R}$ and snow depth was achieved for data over western Michigan in an area where the percentage of forest cover was well documented.

Over heterogeneous mountainous areas different algorithms are needed to retrieve the water equivalent of the snow cover. A mixed pixel model based on vegetation differences has been developed to simulate the microwave brightness temperatures for the Rio Grande basin $\left(3419 \mathrm{~km}^{2}\right)$ in southwestern Colorado (Chang et al., in press). A relationship was obtained between the difference in microwave brightness temperature at two different frequencies ( 18 and $37 \mathrm{GHz}$ horizontal polarization) and the basin-wide average snow water equivalent. The areal snow water equivalent values derived from the model are consistent with values generated by a reliable snowmelt runoff model using snow cover extent data (Chang et al., in press).

A generalized SWE retrieval that includes information about land cover has been reported by Rott and Aschbacher (1989),

$$
\mathrm{SWE}=\mathrm{A}_{1}+\mathrm{A}_{2} \Delta \mathrm{T}_{\mathrm{B}} \mathrm{mm}
$$

where $A_{1}$ represents the offset for a snow-free case and depends on regional variation of land cover type, $A_{2}$ is the coefficient to relate $\Delta T_{B}$ and the SWE, and $\Delta T_{B}$ is the brightness temperature differences between two channels. The value of $A_{2}$ varies greatly depending primarily on the morphology of the snow cover as well as on the obscuration of the surface by vegetation. Kunzi et al. (1982) reported an average value of $A_{2}=4 \mathrm{~mm} / \mathrm{K}$ for their study in Switzerland.
Hallikainen (1984) noted significant variations of $A_{2}$ due to different types of vegetation cover. For specific test areas in Finland he found values of $A_{2}=2.9 \mathrm{~mm} / \mathrm{K}$ for bogland and $5.4 \mathrm{~mm} / \mathrm{K}$ for forest. For an area with $30 \%$ forest cover in central Europe Rott and Aschbacher (1989) found $A_{2}=$ $3 \mathrm{~mm} / \mathrm{K}$.

If a footprint is considered to be a mixed signature with $f \%$ forest cover and $(1-f) \%$ snow cover, then $\Delta T_{B}$ in equation (1) will become

$$
\Delta \mathrm{T}_{\mathrm{BR}}=(1-\mathrm{f})^{*} \Delta \mathrm{T}_{\mathrm{B}}
$$

where $\Delta T_{B R}$ is the residual brightness temperature difference from which the effects of forest cover have been removed, assuming the emissivities of forest for 18 and $37 \mathrm{GHz}$ are the same (Chang et al., 1990c). If $\mathrm{f}$ is not zero, then the $\Delta \mathrm{T}_{\mathrm{BR}}$ in equation (4) should be smaller than the $\Delta T_{B}$ in equation (1). The brightness temperature difference measured using equation (1) to derive SWE would underestimate the actual SWE. The amount of underestimating depends on the fraction of forest cover in equation (4). For the boreal forest of Saskatchewan this fractional value was estimated by using the SWE as measured at snow course sites and the observed SMMR $\Delta \mathrm{T}_{\mathrm{B}}$. The measured SWEs were contoured so that an average weighted value was derived for each SMMR pixel. Snow depth values were used to infer the SWE when this data was not available. Figure 3 shows the relationship of the calculated $\Delta T_{B R}$ and the estimated SWE as a function of fractional forest cover. For example, a SWE weighted value of $40 \mathrm{~mm}$ and a $\Delta T_{B R}$ of $5 \mathrm{~K}$ would result in a fractional forest cover of 0.4 .

To study the effect of vegetation on spaceborne SWE retrieval, Nimbus-7 SMMR-derived snow data and conventional snow course data from the northern portion of the province of Saskatchewan, Canada (Fig. 4) during the winter

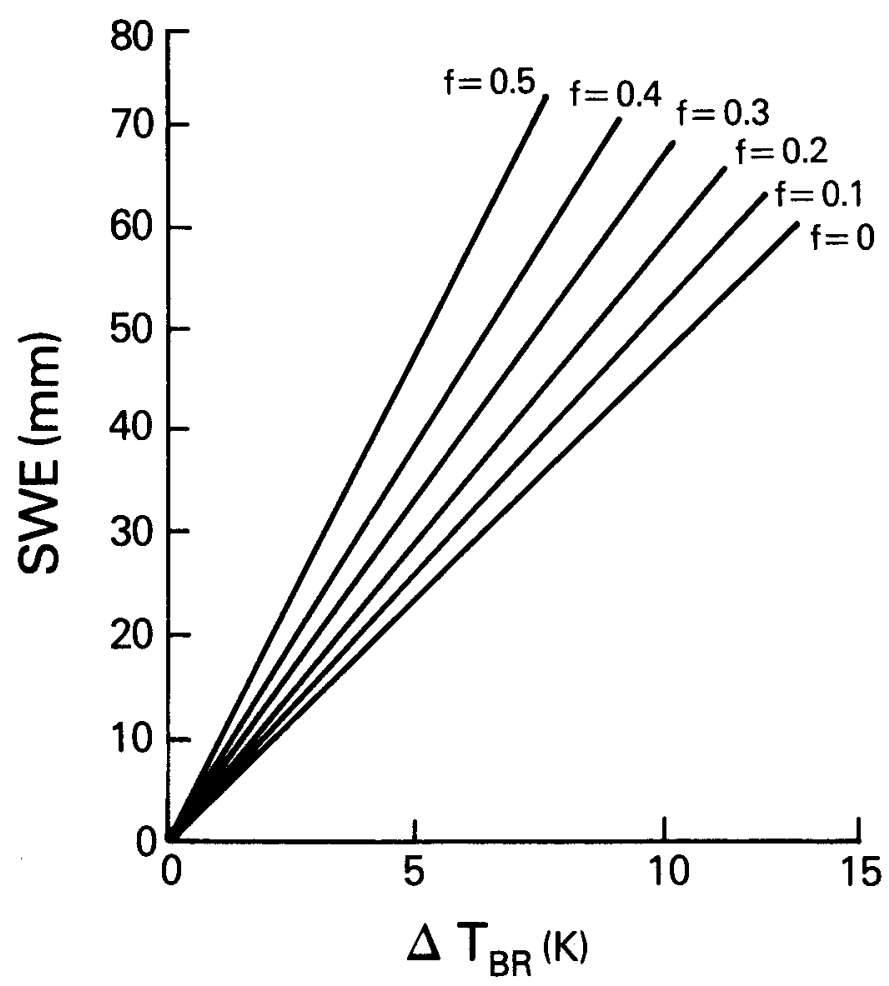

FIG. 3. Relationship of the calculated change in microwave brightness temperature and the estimated snow water equivalent as a function of fractional forest cover. 
months (January-April) for the years 1980-84 were compared. The SMMR and snow course data were both sampled near the beginning of each month.

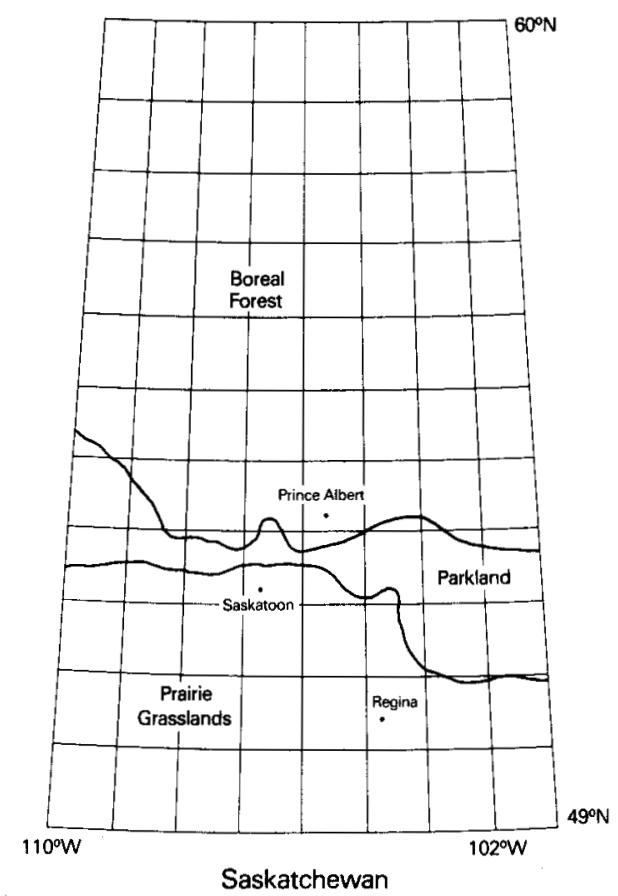

FIG. 4. Map of vegetation districts for Saskatchewan with superimposed SMMR grid network.

\section{RESULTS AND DISCUSSION}

As expected, difference in forest density and species type affected the microwave emissivity (Hallikainen et al., 1988) (Fig. 5). It can be seen from Figure 5 that most of the data points are located above the 1:1 line. This is because the boreal forest reduced the sensitivity of the snow depth determination, and therefore SWE is underestimated using equation (1). By using the percentage of boreal forest cover, according to Figure 3, the difference between the measured and the estimated SWE is smaller (Table 1). The standard error reduces from $2.7 \mathrm{~cm}$ to $2.1 \mathrm{~cm}$. Thus, this adjusted algorithm reduces the variability of the SWE in the forested areas of Saskatchewan by about $22 \%$.

For northern Saskatchewan using a fractional forest cover of 0.4 brings the adjusted algorithm (equation 4 ) into accord with the observations. In actuality the forest cover may be higher. But it should be kept in mind that significant areas of the boreal forest in northern Saskatchewan are populated by lakes and bogs, which are included when estimating the percentage of forest cover in a given SMMR footprint.

This technique, however, is not necessarily valid for other portions of the North American boreal forest zone or for the boreal forest of Eurasia. In fact, in the boreal forest of Quebec the SMMR data has been found to considerably underestimate the snow depth. In some months the SMMRderived snow depth is as much as $50 \mathrm{~cm}$ less than that measured on the ground.

This finding was verified using hand-held radiometers at

TABLE 1. Comparisons of ground-based and SMMR-derived snow water equivalent measurements (in $\mathrm{cm}$ ) in the boreal forest of Saskatchewan

\begin{tabular}{|c|c|c|c|c|c|c|}
\hline & & & \multicolumn{4}{|c|}{ SMMR-derived estimates* } \\
\hline & \multicolumn{2}{|c|}{$\begin{array}{l}\text { Ground-based } \\
\text { measurements }\end{array}$} & \multicolumn{2}{|c|}{$\begin{array}{l}\text { Unadjusted } \\
\text { algorithm } \\
\text { (equation 1) }\end{array}$} & \multicolumn{2}{|c|}{$\begin{array}{c}\text { Adjusted } \\
\text { algorithm } \\
\text { (equation 4) }\end{array}$} \\
\hline & Mean & S.D. & Mean & S.D. & Mean & S.D. \\
\hline \multicolumn{7}{|l|}{1980} \\
\hline Jan & 4.8 & 1.0 & 2.9 & 2.0 & 3.5 & 2.0 \\
\hline Feb & 9.0 & 2.7 & 6.5 & 2.9 & 9.2 & 2.9 \\
\hline Mar & 10.5 & 3.8 & 8.3 & 3.3 & 11.5 & 3.3 \\
\hline Apr & 7.7 & 2.4 & 6.7 & 3.4 & 9.0 & 3.4 \\
\hline \multicolumn{7}{|l|}{1981} \\
\hline Jan & 9.1 & 2.6 & 3.2 & 2.5 & 4.3 & 2.5 \\
\hline Feb & 9.4 & 1.3 & 6.9 & 3.2 & 10.3 & 3.2 \\
\hline Mar & 9.5 & 3.1 & 6.8 & 4.0 & 11.2 & 4.0 \\
\hline Apr & 5.8 & 3.9 & 3.5 & 3.7 & 7.8 & 3.7 \\
\hline \multicolumn{7}{|l|}{1982} \\
\hline Jan & 9.2 & 1.8 & 5.6 & 2.9 & 8.4 & 2.9 \\
\hline Feb & 11.0 & 1.8 & 9.2 & 3.2 & 13.1 & 3.2 \\
\hline Mar & 13.0 & 2.3 & 10.8 & 3.5 & 15.2 & 3.5 \\
\hline Apr & 11.5 & 2.2 & 9.2 & 4.8 & 15.2 & 4.8 \\
\hline \multicolumn{7}{|l|}{1983} \\
\hline Jan & 10.7 & 2.2 & 5.5 & 2.9 & 7.0 & 2.9 \\
\hline Feb & 13.8 & 3.2 & 9.4 & 3.0 & 12.4 & 3.0 \\
\hline Mar & 14.2 & 3.4 & 8.0 & 3.8 & 12.1 & 3.8 \\
\hline Apr & 12.5 & 3.2 & 9.4 & 4.0 & 14.3 & 4.0 \\
\hline \multicolumn{7}{|l|}{1984} \\
\hline Jan & 6.4 & 2.2 & 5.4 & 3.2 & 4.7 & 3.2 \\
\hline Feb & 8.7 & 3.7 & 6.4 & 3.1 & 6.4 & 3.1 \\
\hline \multirow[t]{2}{*}{ Mar } & 8.9. & 2.7 & 6.4 & 3.4 & 9.0 & 3.4 \\
\hline & 9.8 & 2.6 & 6.8 & 3.3 & 9.7 & 3.3 \\
\hline
\end{tabular}

* The standard deviation is the same for the unadjusted and adjusted SMMR data. The standard error for the unadjusted algorithm it is $2.7 \mathrm{~cm}$ and for the adjusted algorithm it is $2.1 \mathrm{~cm}$. 


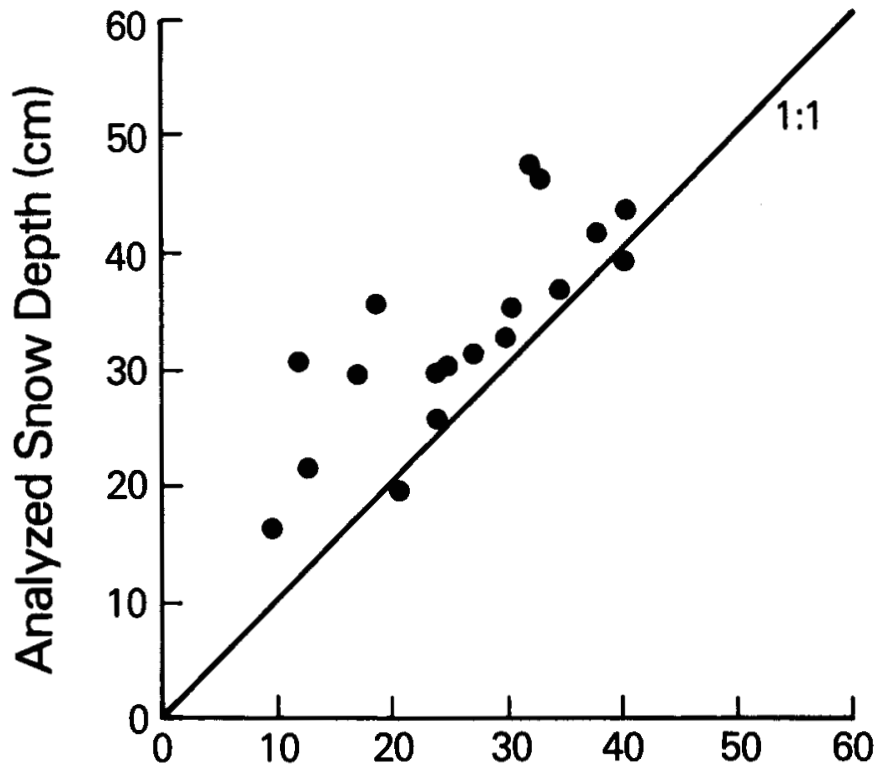

SMMR Derived Snow Depth $(\mathrm{cm})$

FIG. 5. Scattergram for SMMR-derived snow depth and snow depth derived from ground-based observations for the boreal forest of Saskatchewan.

the Howland Experimental Forest test site in north-central Maine. This site is in a predominantly spruce pine forest. A $26 \mathrm{~m}$ tower extends above the canopy, and a $35 \mathrm{GHz}$ radiometer positioned on top of the tower was utilized to make measurements of snow covering the forest floor. Preliminary data are available for the winter of 1990, which is the first year of operation at this site (Table 2). At an angle of incidence of $50^{\circ}$ (the look angle of SMMR) the canopy completely obscured the snow surface, and the $T_{B}$ at $35 \mathrm{GHz}$ averaged about $240 \mathrm{~K}$. When the radiometer was pointed towards an area devoid of any vegetation the average $T_{B}$ was about 186 $\mathrm{K}$. The average snow depth in the view of the radiometer (at $50^{\circ}$ ) was approximately $50 \mathrm{~cm}$. When directed at an area of deciduous saplings the $T_{B}$ averaged about $206 \mathrm{~K}$. The snow depth here averaged about $60 \mathrm{~cm}$ (Table 2). These experiments show the influence of the canopy when monitoring the snow surface. Regardless of snow depth, the dense coniferous canopy, when viewed at an angle of $50^{\circ}$, absorbs most of the upwelling radiation that emanates from the ground in the $35 \mathrm{GHz}$ region. Hallikainen et al. (1988) showed that annual variations in brightness temperature in forests are small at the 10,18 , and $37 \mathrm{GHz}$ frequencies for both horizontal and vertical polarizations. This demonstrates the limited capability of microwave radiation in penetrating dense vegetation. Thus, in dense forests current microwave methods of estimating snow depth are not viable.

Figure 6 is a composite minimum brightness chart for 11-18 January 1982. The most dense portions of the boreal forests of Canada are defined by very low surface brightness in eastern Manitoba, southern Ontario, and southern Quebec (Scialdone and Robock, 1987). SMMR data for mid-January 1982 show these areas to have shallow snow $(<10 \mathrm{~cm})$. Actual snow depths were greater than $25 \mathrm{~cm}$ (Canadian Climate Centre, 1982).

Crown closure, basal area (the cross-sectional area of tree stems per unit ground area), and foliage biomass are all inversely related to visible reflectance and scene brightness of Landsat (MSS and TM) and NOAA (AVHRR) imagery (Franklin, 1986). As crown closure and basal area increase, reflectance decreases in the photosynthetic regions of the visible spectrum due to increased leaf area, absorption, and shadowing within the canopy.

TABLE 2. Effect of vegetation on microwave brightness temperatures as measured at the Howland Experimental Forest* in north-central Maine

\begin{tabular}{lll}
\hline \hline Azimuth & Incidence angle & Brightness temperature $\left({ }^{\circ} \mathrm{K}\right)$ \\
\hline $270^{\circ}$ & $60^{\circ}$ & 244 \\
& $50^{\circ}$ & 245 \\
& $40^{\circ}$ & 244 \\
$0^{\circ}$ & $20^{\circ}$ & 241 \\
radiometer pointed toward deciduous saplings \\
$180^{\circ}$ & $50^{\circ}$ & 247 \\
radiometer pointed toward non-vegetated area \\
$90^{\circ}$ & $70^{\circ}$ & 169 \\
& $60^{\circ}$ & 173 \\
& $50^{\circ}$ & 196 \\
& $40^{\circ}$ & 202 \\
$30^{\circ}$ & 203
\end{tabular}

radiometer pointed toward sky (zenith)

005 * Howland Experimental Forest - mature hemlock, spruce, and white pine.
Some snow present in the forest canopy. Snow depth on the forest floor
averages approximately $50 \mathrm{~cm}$ and temperature $-12^{\circ} \mathrm{C}$. Measurements made
with a $35 \mathrm{GHz}$ radiometer.

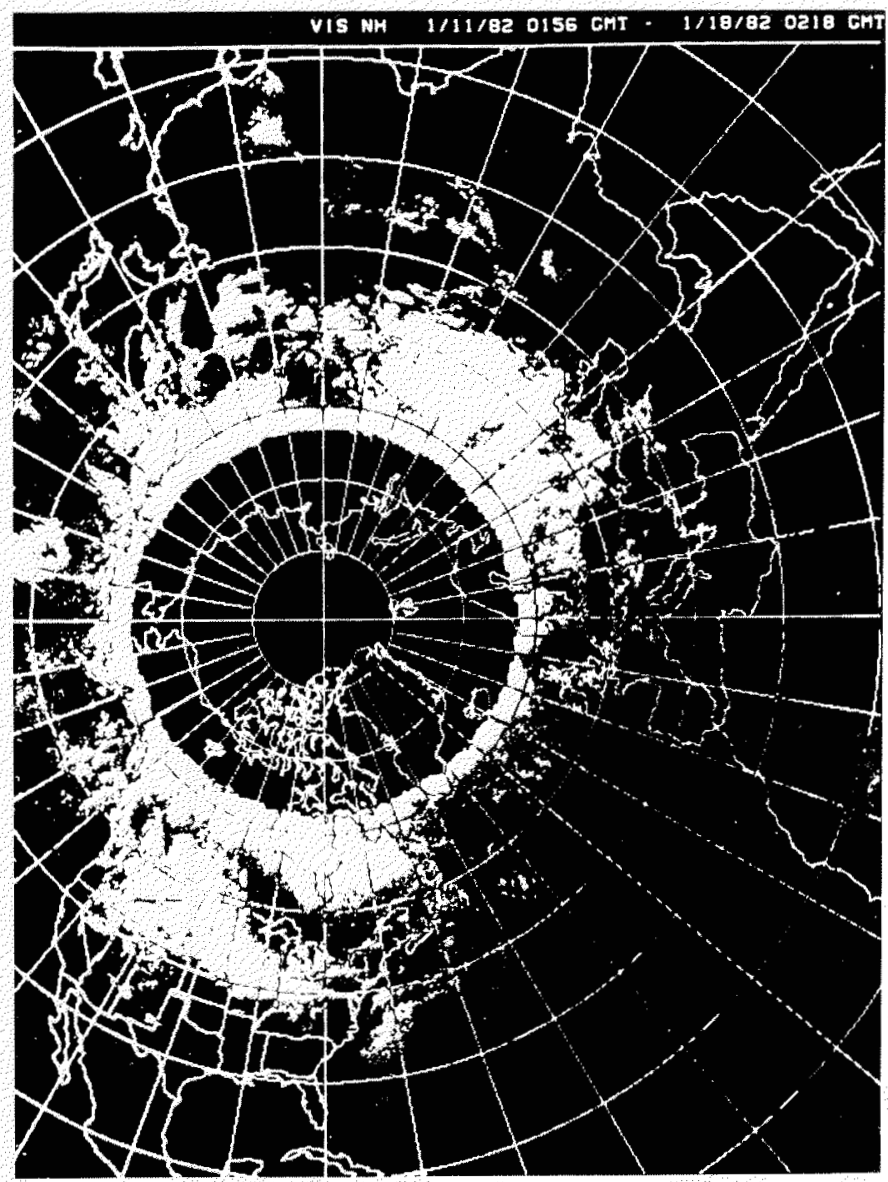

FIG. 6. Composite minimum brightness chart for 11-18 January 1982. 
Despite greater interception of snowfall by the forest canopy, deeper snow typically accumulates in those areas of the boreal forest that appear dark on visible satellite imagery. This can be attributed to retarded snowmelt as a result of reduced solar radiation. Approximately $25 \%$ of the boreal forest in the Northern Hemisphere is most likely too dense to allow satisfactory snow depth determination using passive microwave algorithms. More realistic snow storage estimates may be attained if prescribed snow depth amounts, based on climatological data, are used instead. One way of doing this perhaps is to use the reflectance of sunlight in the visible wavelengths in combination with the $T_{B}$ difference between 18 and $37 \mathrm{GHz}$ data to assess where the forests are too dense to use microwave techniques for snow depth determination. Initial results indicate that if the reflectance is less than 0.3 and the $T_{B}$ difference is less than $10 \mathrm{~K}$, then prescribed snow depths should be used. The resultant snow depths would be more representative of a dense boreal forest snowpack than the depths obtained using the SMMR algorithms described earlier.

\section{CONCLUSIONS}

The arctic region is influenced by energetic subpolar systems transporting heat and momentum into the region, and it, in turn, influences the general circulation of the atmosphere by acting as a heat sink (Vowinckel and Orvig, 1970). For a better understanding of the energy exchange among the atmosphere, the snowpack, and the ground, snow depth and snow extent must be known for large areas.

Microwave algorithms have enabled measurements to be made of snow extent and snow volume on a regional and global basis. However, retrieval of snow parameters is complicated in forests due to their emission and absorption properties. Algorithms that are able to incorporate information on the fractional forest cover within a microwave pixel provide more reliable estimates of the snow water equivalent and thickness of a snowpack. Efforts are currently under way to estimate the fractional forest cover using only microwave measurements rather than relying on a combination of ground-based measurements and microwave techniques. But in the most densely forested areas, such as in the boreal forest of Ontario and Quebec, microwave techniques alone are not adequate in estimating the volume of snow underlying the forest canopy.

\section{ACKNOWLEDGEMENTS}

The authors would like to thank Mike Goltz, of the Department of Plant, Soil and Environmental Science at the University of Maine, and International Paper in Bangor, Maine, for assistance in providing a test site facility. Additionally, William Kovalick, of STX in Lanham, Maryland, and Forrest Scott and John Lee, of the Department of Plant, Soil and Environmental Science at the University of Maine, were very helpful in collecting data and making snowpack measurements. Also, the authors express their appreciation to Victor van Katwijk, of the USDA Hydrology Laboratory in Beltsville, Maryland, and to the referees who reviewed this paper for their helpful comments and suggestions.

\section{REFERENCES}

BARRY, R.G. 1984. Possible $\mathrm{CO}_{2}$-induced warming effects on the cryosphere. In: Morner, N.A., and Karlen, W., eds. Climate changes on a yearly to millennial basis. Hingham: D. Reidel. 571-604.
CANADIAN CLIMATE CENTER. 1982. Climatic perspectives. Atmospheric Environment Service 4(2):3-7.

CHANG, A.T.C., GLOERSEN, P., SCHMUGGE, T., WILHEIT, T., and ZWALLY, H.J. 1976. Microwave emission from snow and glacier ice. Journal of Glaciology 16:23-39.

CHANG, A.T.C., FOSTER, J.L., and HALL, D.K. 1987. Nimbus-7 derived global snow cover parameters. Annals of Glaciology 9:39-44.

CHANG, A.T.C., FOSTER, J.L., and HALL, D.K. 1990a. Satellite sensor estimates of Northern Hemisphere snow volume. International Journal of Remote Sensing 11(1):167-172.

CHANG, A.T.C., FOSTER, J.L., HALL, D.K., POWELL, H.W., and CHIEN, Y.L. 1990b. Nimbus-7 derived global snow cover and snow depth data set. The Pilot Land Data System. Greenbelt, Maryland: NASA/Goddard Space Flight Center. 38 p.

CHANG, A.T.C., FOSTER, J.L., and HALL, D.K. 1990c. Effect of vegetation cover on microwave snow water equivalent estimates. Proceedings of the International Symposium on Remote Sensing and Water Resources. Enschede: International Association of Hydrogeologists and The Netherlands Society for Remote Sensing. 137-145.

CHANG, A.T.C., FOSTER, J.L., and RANGO, A. In press. Utilization of surface composition to improve the microwave determination of snow water equivalent in a mountain basin. International Journal of Remote Sensing.

CHOUDBURY, B.J., TUCKER, C.J., GOLUS, R.E., and NEWCOMB, W.W. 1987. Monitoring vegetation using Nimbus-7 scanning multichannel microwave radiometer's data. International Journal of Remote Sensing 8:533-538.

FOSTER, J.L., HALL, D.K., and CHANG, A.T.C. 1987. Remote sensing of snow. Eos Transactions, AGU 68:681-684.

FRANKLIN, J. 1986. Thematic mapper analysis of coniferous forest structure and composition. International Journal of Remote Sensing 7:1287-1301.

FREESE, F. 1962. Elementary forest sampling. U.S. Department of Agriculture, Forest Service Agricultural Handbook No. 232. 91 p.

HALL, D.K., FOSTER, J.L., and CHANG, A.T.C. 1982. Measurement and modeling emission from forested snowfields in Michigan. Nordic Hydrology 13:129-138.

HALLIKAINEN, M.T. 1984. Retrieval of snow water equivalent from Nimbus-7 SMMR data: Effect of land-cover categories and weather conditions. Journal of Oceanic Engineering 9:372-376.

HALLIKAINEN, M.T., JOLMA, P.A., and HYYPPA, J.M. 1988. Satellite microwave radiometry of forest and surface types in Finland. IEEE Transactions of Geoscience and Remote Sensing 26:622-628.

KONG, J.A., SHIN, R., SHIUE, J.C., and TSENG, L. 1979. Theory and experiment for passive microwave remote sensing of snowpacks. Journal of Geophysical Research 84:5669-5673.

KUNZI, K.F., PATIL, S., and ROTT, H. 1982. Snow-cover parameters retrieved from Nimbus-7 Scanning Multichannel Microwave Radiometer (SMMR) data. IEEE Transactions of Geoscience and Remote Sensing 20:452-467.

NATIONAL GEOGRAPHIC SOCIETY. 1985. Atlas of North America. W.E. Garrett, ed. Washington, D.C. 160-171.

RANGO, A., CHANG, A.T.C., and FOSTER, J.L. 1979. The utilization of spaceborne microwave radiometers for monitoring snowpack properties. Nordic Hydrology 10:25-40.

ROTT, H., and ASCHBACHER, J. 1989. On the use of satellite microwave radiometers for large-scale hydrology. Proceedings IAHS 3rd International Assembly on Remote Sensing and Large-Scale Global Processes, Baltimore, Maryland, May 1989. 21-30.

SCIALDONE, J., and ROBOCK, A. 1987. Comparison of Northern Hemisphere snow cover data sets. Journal of Climate and Applied Meteorology 26(1):53-68.

STILES, H.W., and ULABY, F.T. 1980. The active and passive microwave response to snow parameters. Part I: wetness. Journal of Geophysical Research 85:1037-1044.

TIURI, M., and HALLIKAINEN, M. 1981. Remote sensing of snow depth by passive microwave satellite observations. Proceedings of the 11th European Microwave Conference, Amsterdam, September 1981. 233-238.

ULABY, F.T., and JEDLICKA, R.P. 1984. Microwave dielectric properties of plant materials. IEEE Transactions of Geoscience and Remote Sensing 22:406-414.

VOWINCKEL, E., and ORVIG, S. 1970. The climate in the north polar basins. In: World Survey of Climatology. Vol. 14, Climate of the Polar Regions. Amsterdam: Elsevier. 129-252.

WANG, J.R. 1985. Effect of vegetation on soil moisture sensing observed from orbiting microwave radiometers. Remote Sensing of Environment 17:141-151.

WOO, M.K., and STEER, P. 1985. Simulation of snow depth in a forest. Proceedings of the 1985 Eastern Snow Conference, Montreal, Canada. 44-54. 